\title{
LA-UR- $98-1806$
}

Approved for public release ofstribution is unlimited.

Submitted to:

1998 Symposium on Radiation

Measurements and Applications, Ann Arbor, Michigan, May 12-14, 1998

Colin M. Bartle Robert C. Haight RECEIVFD OCT $0 \& 1998$ OSTI

SMALL INORGANIC SCINTILLATORS AS NEUTRON DETECTORS

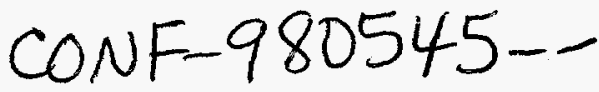

Author(s):

\section{Los Alamos}

\section{NATIONAL LABORATORY}

Los Alamos National Laboratory, an affimative actionlequal opportunity employer, is operated by the University of Califorivia for the U.S. Department of Energy under contract W-7405-ENG-36. By acceptance of this article, the publisher recognizes that the U.S. Government refains a nonexclusive, royalty-free license to publish or reproduce the published form of this contribution, or to allow others to do so, for U.S. Government purposes. Los Alamos National Laboratory requests that the publisher identify this article as work performed under the auspices of the U.S. Department of Energy. The Los Alamos National Laboratory strongly supports academic freedom and a researcher's right to publish; as an institution, however, the Laboratory does not endorse the viewpoint of a publication or guarantee its technical correctness. 


\section{DISCLAIMER}

This report was prepared as an account of work sponsored by an agency of the United States Government. Neither the United States Government nor any agency thereof, nor any of their employees, makes any warranty, express or implied, or assumes any legal liability or responsibility for the accuracy, completeness, or usefulness of any information, apparatus, product, or process disclosed, or represents that its use would not infringe privately owned rights. Reference herein to any specific commercial product, process, or service by trade name, trademark, manufacturer, or otherwise does not necessarily constitute or imply its endorsement, recommendation, or favoring by the United States Government or any agency thereof. The views and opinions of authors expressed herein do not necessarily state or reflect those of the United States Governmeat or any agency thereof. 


\section{DISCLAIMER}

Portions of this document may be illegible in electronic image products. Images are produced from the best available original document. 


\title{
Small Inorganic Scintillators as Neutron Detectors
}

\author{
C. M. Bartle \\ Institute of Geophysical and Nuclear Sciences, Lower Hutt, New Zealand \\ and \\ R. C. Haight \\ Los Alamos National Laboratory, Los Alamos, NM 87545 USA
}

\begin{abstract}
Small organic scintillators that exhibit pulse shape differences (PSD) in response to charged particles have been investigated as possible neutron detectors in the energy range from 1 to $200 \mathrm{MeV}$. Neutrons in this energy range can induce reactions such as (n,p) and $(\mathrm{n}, \mathrm{alpha})$ in these scintillators, and the cross sections for these reactions vary with energy. Pulse-height and PSD distributions were measured as a function of neutron energy for small crystals of $\mathrm{NaI}(\mathrm{Tl})$ and $\mathrm{CsI}(\mathrm{Tl})$ at the LANSCE-WNR pulsed spallation neutron source. PSD information indicating the relative numbers of protons and alphas produced can give information about the neutron spectrum in fast-neutron radiation fields such as those encountered in space exploration.
\end{abstract}

\section{Introduction}

Characterization of neutron spectra is important in a very wide range of applications, including those of remote sensing [1,2]. Neutron fields with energies from thermal to fast neutron energies of a few $\mathrm{MeV}$ can be characterized by a series of detectors including Bonner spheres.[3] For higher neutron energies, larger Bonner spheres or modified spheres are used, and these can be quite massive and have diameters approaching $0.5 \mathrm{~m}$. If mass or size is an issue, such as in space exploration, medical therapy or applications where then neutron field is not to be greatly perturbed by the instrument, then smaller, lower mass detectors would be preferred.

Neutron reactions in inorganic scintillators such as $\mathrm{NaI}(\mathrm{Tl})$ or $\mathrm{CsI}(\mathrm{Tl})$ have thresholds in the few $\mathrm{MeV}$ range, for example for $(\mathrm{n}, \mathrm{p})$ and $(\mathrm{n}$,alpha) reactions as given in Table $\mathrm{I}$. Spallation reactions would have even higher thresholds, and, if they could be identified by their PSD signal, then they would serve as a further threshold detectors. These two scintillators are known to have good pulse-shape discrimination (PSD) properties even for 
neutron-induced reactions, e.g [4-12] so that events in which charged particles result from neutron reactions can be separated from gamma-ray events (either from external gamma-ray sources or (n,n'gamma) interactions in the crystals themselves). Furthermore, both scintillators exhibit PSD that allows the additional separation of protons and alpha

particles. These properties suggest that such scintillators can be used as neutron detectors, and because of their different effective reaction thresholds, could be used as low-mass instruments to characterize neutron spectra in the several $\mathrm{MeV}$ region and above.

Previous studies (e.g. Ref. [4]) have shown that such an approach is useful in characterizing neutron field up to $12 \mathrm{MeV}$ and that PSD is observed for higher neutron energies [5-12]. In this work, we investigate the dependence of the PSD information as a function of neutron energy in the range from a few MeV to over $200 \mathrm{MeV}$. If the PSD spectrum varies strongly with incident neutron energy, then this information would be useful in characterizing the energies of neutron fields.

\section{Experimental method}

Neutrons were produced by the LANSCE-WNR pulsed spallation neutron source [14]. The detector was located in a detector station 41 meters from the source at a neutron production angle of 30-degrees. The neutron flux spectrum extended from about $1 \mathrm{MeV}$ to several hundred $\mathrm{MeV}$. The present experiment was similar to that described previously [11] with the exception that the beam was collimated to approximately $1 \mathrm{~cm}$ in diameter by a steel and copper collimator approximately $1 \mathrm{~m}$ long followed by a "cleanup" collimator, $1.2 \mathrm{~cm}$ in diameter. Lead was placed in the beam to reduce the counting rate to an acceptable value. A further difference was that the relative neutron flux was monitored by an NE213 detector between the principal and cleanup collimators. An absolute measurement of the flux was made subsequently by replacing the inorganic scintillator with a fission chamber. Pulse height and pulse shape signals were obtained in the usual manner and recorded event-by-event for both the NE213 detector and for the inorganic scintillator under investigation.

The scintillators were $2.5 \mathrm{~cm}$ in diameter and $1.2 \mathrm{~cm}$ thick. The NaI(Tl) scintillator was hermetically sealed in an aluminum can with a glass window, whereas the CsI(Tl) scintillator did not have a housing but was instead held against the RCA 8575 photomultiplier tube with aluminum foil which also served as a reflector for the scintillation light.

We used standard electronics to analyze the signals. A standard zero-crossing technique was used to characterize the pulse shape from a delay-line amplifier with 1 microsecond delay lines. The gains and timing were changed between the NaI(Tl) and CsI(TI) experiments because of the significant difference in their pulse shapes and relative magnitudes for the same energy charged particle. An event included the following information: time-of-flight to indicate the neutron energy, pulse height, and pulse shape. The data were saved on tape for later replay. 


\section{Results}

Representative pulse height vs. pulse shape distributions are shown in Figure 1 for the $\mathrm{NaI}(\mathrm{Tl})$ and $\mathrm{CsI}(\mathrm{Tl})$ scintillators for the complete neutron energy range incident on the sample. Loci suggesting proton, deuteron and alpha particles can be seen, and the results are similar to that of Ref. [3]. If we take those events with a given range of pulse heights, we can extract the PSD signal as a function of time-of-flight of the neutrons (Figures 2) and therefore as a function of neutron energy. Results for various neutron

energy bins are shown in Figure 3, where one sees the effect of the ${ }^{23} \mathrm{Na}(\mathrm{n}, \mathrm{p})$ threshold being lower than that for the ${ }^{23} \mathrm{Na}(\mathrm{n}, \mathrm{d})$ reaction. Although the PSD spectra do not change dramatically for much higher neutron energies, it should be noted that for the highest neutron energies, the regions between the hydrogen isotopes (protons and deuterons mostly) and alphas peaks fill in. We believe this is due to reactions where more than one charged particle is produced (such as in the ( $n, 2 \mathrm{p}$ ) reaction).

\section{Conclusions}

Pulse-shape information from inorganic scintillators gives an index of neutron energies in an unknown field. The PSD signal is particularly characteristic of neutrons just above thresholds for $(n, p)$ and (n,alpha) reactions and therefore for neutron energies in the 6-15 $\mathrm{MeV}$ range. Because of the reaction thresholds, the PSD signals can be used to discriminate well against neutrons of energies below the thresholds. For much higher neutron energies, charged-particle production cross sections vary rather slowly with neutron energy and the PSD signal does not give as definitive information on neutron energies. Neutron energies above $50 \mathrm{MeV}$ are indicated, however, by the filling-in of the regions between the charged particle groups, e.g. between protons, deuterons and alphas, due to events where more than one charged particle is produced, e.g. by ( $n, p$ alpha), $(n, 2 p)$, etc. reactions. It was hoped that spallation reactions could be uniquely identified from PSD information to provide yet another signature of the neutron energy. However, we do not believe we have seen such events other than those that fill in the regions between the protons and alphas.

As shown in Figure 1, separation of charged particles from gamma rays increases greatly for decreasing pulse height. It is therefore possible that the PSD signal could be used to indicate changes in the gain of the pulse height, for example from deterioration of the photomultiplier tube. The PSD signal, if it is simply related to the time constants of the pulse, should be independent of pulse height. For a given particle type, the time constant of the pulse is, however, also directly related to energy of the particle due to the variation in ionization density with particle energy. This internal method of detecting gain changes would not be as sensitive as with an internal radiation source, but it might have some operational advantages. 


\section{References:}

[1] W. C. Feldman, W. V. Boynton, and D. M. Drake, "Planetary Neutron Spectroscopy from Orbit," in Remote Geochemical Analysis: Elemental and Mineralogical Composition, ed. Carle M. Pieters and Peter A. J. Englert, Cambridge University Press (1993) pp. 213 234.

[2] Yu. A. Surkov, O. P. Shcheglov, M. L. Ryvkin, and O. A. Vinogradova, "Neutron Spectrometry," in Remote Geochemical Analysis: Elemental and Mineralogical Composition, ed. Carle M. Pieters and Peter A. J. Englert, Cambridge University Press (1993) pp. 427-436.

[3] G. F. Knoll, Radiation Detection and Measurement, (John Wiley and Sons, New York, 1979), p. 556.

[4] D. M. Whittal and C. M. Bartle, Nucl. Instr. and Meth. A247 (1986) 390-394

[5] G. H. Share, J. D. Kurfess, and R. B. Theus, Nucl. Instr. and Meth. 148, 531 (1978).

[6] W. R. Dixon, Nucl. Phys. 42, 27 (1963).

[7] M. Bormann, Z. Naturforschung 17a, 479 (1962).

[8] T. Matulewisz, E. Grosse, H. Emling, H. Grein, R. Kulessa, F. B. Baumann, G. Domogala and H. Freiesleben, Nucl. Instr. and Meth. 274 (1989) 501.

[9] C. M. Bartle, Nucl. Instr. and Meth. 124, 547 (1975).

[10] J. J.. Van Ruyven, Z. Sujkowski, W. H. A. Hesselink and H. Verheul, Nucl. Instr. and Meth. 216, 141 (1983).

[11] A. Bol, P. Leleux, P. Lipnik, P. Macq and A. Ninane, Nucl. Instr. and Meth. 202, 511 (1982)

[12] O. Hausser, M. A. Lone, T. K. Alexander and S. A. Kushneriuk, Nucl. Instr. and Meth. 213, 301(1983).

[13] ENDF/B-VI Evaluated Nuclear Data File, National Nuclear Data Center, Brookhaven National Laboratory, http://www.nndc.bnl.gov.

[14] P. W. Lisowski, C. D. Bowman, G. J. Russell, S. A. Wender, Nucl. Sci. Eng. 106, 208 (1990). 
[15] C. M. Bartle and R. C. Haight, "Response of Alkali Halide Scintillators to Neutrons from 5 to $100 \mathrm{MeV}$," Proc. Int. Conf. Nuclear Data for Science and Technology, ed. J.K. Dickens, Gatlinburg, Tennessee, May 9-13, 1994 (American Nuclear Society, LaGrange Park, Illinois, 1994) p. 157.

\section{Table I}

Effective thresholds in $\mathrm{MeV}$ of neutron reactions that result in charged particles:*

$\begin{array}{llcc} & (\mathrm{n}, \mathrm{p}) & (\mathrm{n}, \mathrm{d}) & (\mathrm{n}, \mathrm{alpha}) \\ \mathrm{Na} & 6 & 9 & 8 \\ \mathrm{I} & 9 & 13 & 11 \\ \mathrm{Cs} & 8 & 12 & 10\end{array}$

* data from ENDF/B-VI evaluations of [13], and, for (n,d) which is not included in the evaluations for these materials, estimates from (n,p) and the difference in $Q$-values. 


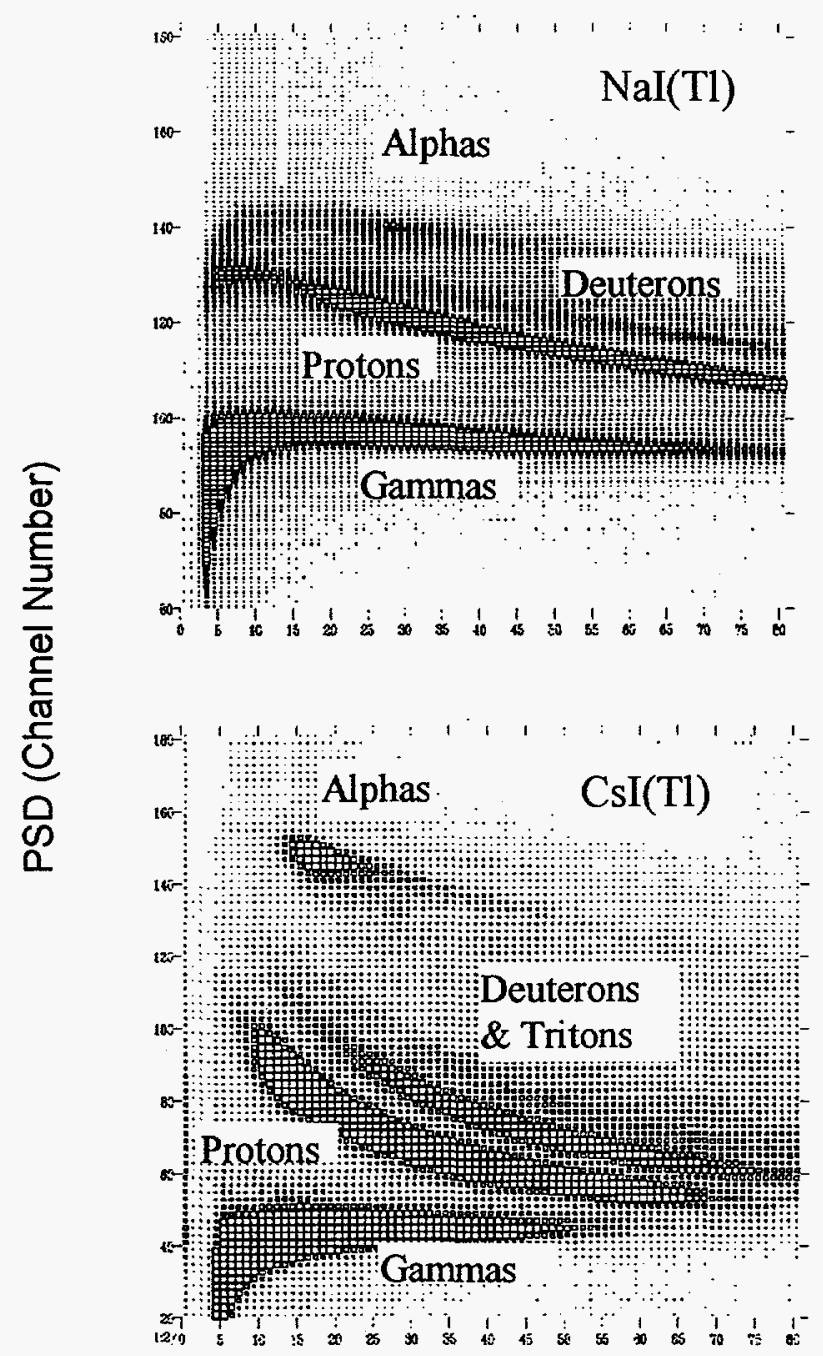

Pulse Height (Channel Number)

Figure 1 - Pulse shape (PSD) signal versus pulse height for the two scintillators irradiated with neutrons from the LANSCE-WNR spallation neutron source. The different particle groups are labeled. 


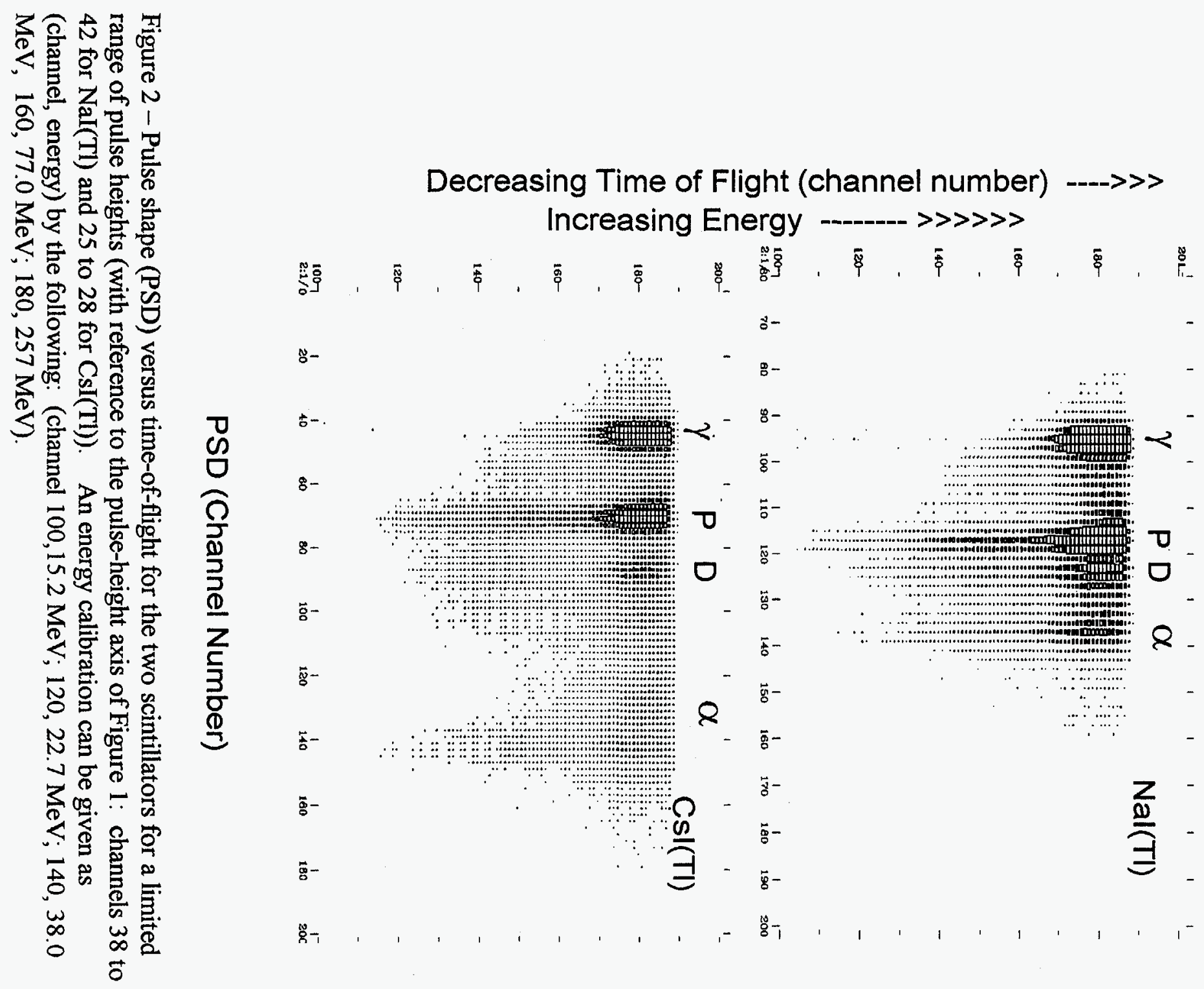



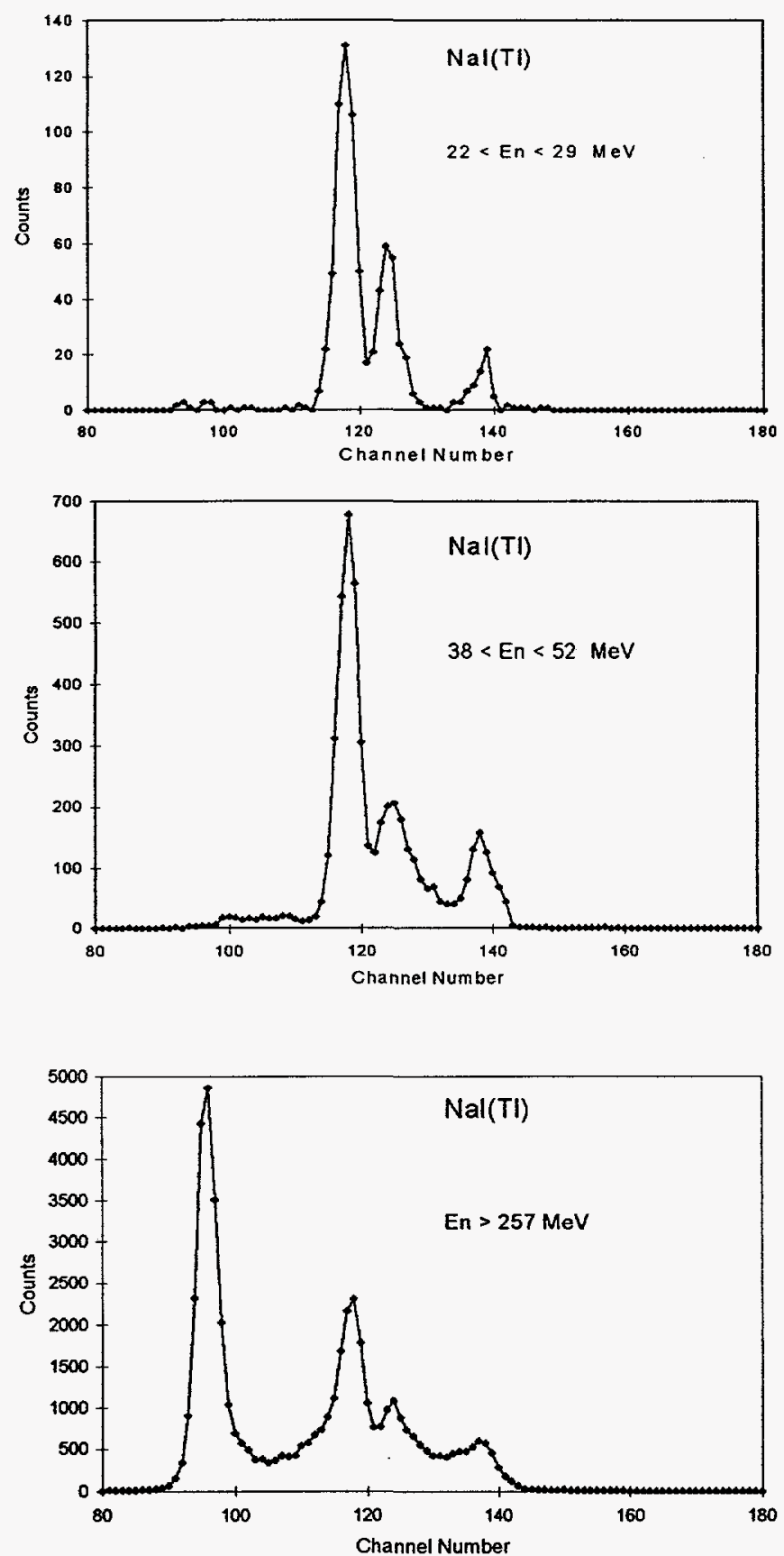

Figure 3 - PSD spectra from NaI(Tl) for different neutron energy bins. These data are simple projections of those given in Figure 2, with the same criterion on pulse height. Note the filling-in around channel 130 for the higher neutron energies. 

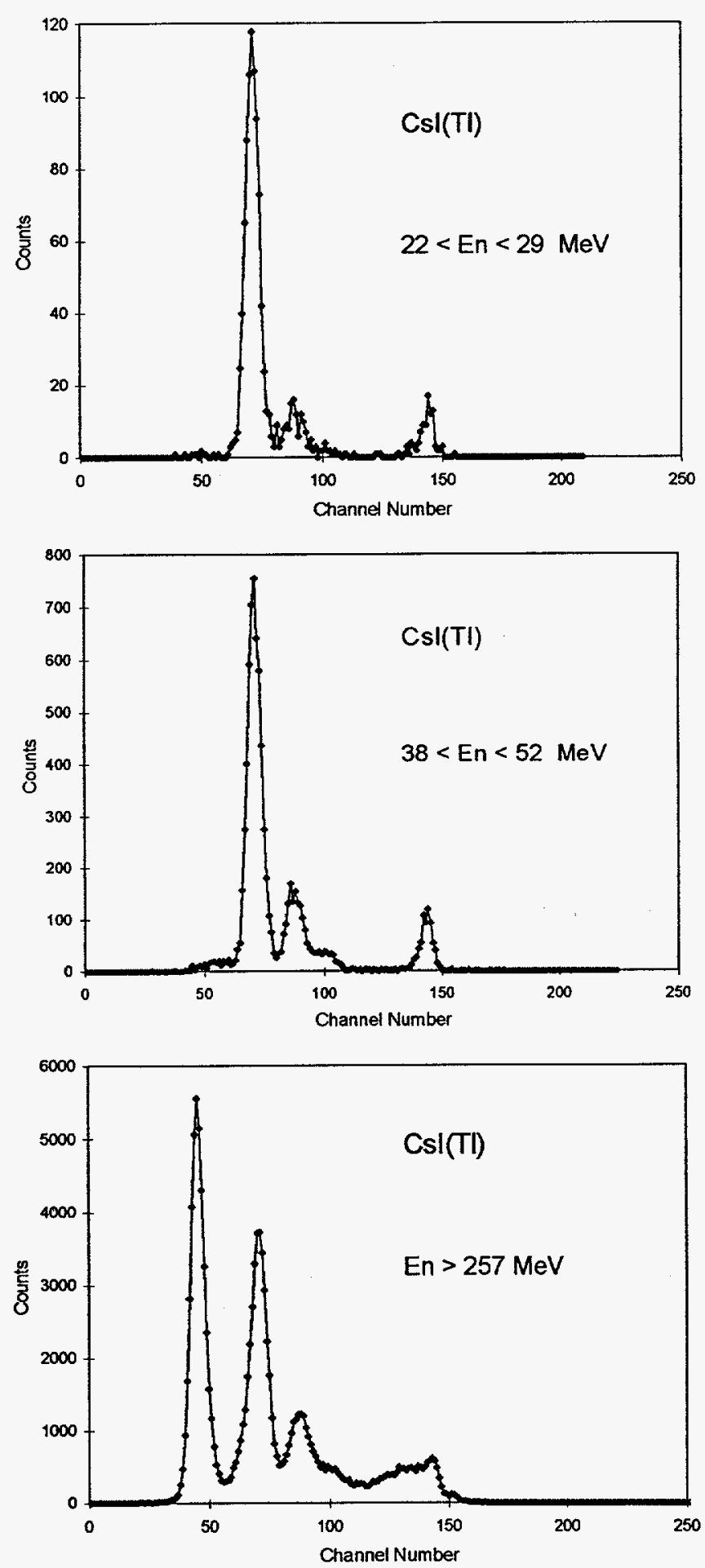

Figure 4 - PSD spectra from CsI(Tl) for different neutron energy bins. These data are simple projections of those given in Figure 2, with the same criterion on pulse height. Note the filling-in around channel 120 for the higher neutron energies. 